\title{
Whispering of the city: Characteristics and origin of environmental shaking in the Taipei metropolitan area
}

Kate Huihusan Chen ( $\nabla$ katepili@gmail.com )

National Taiwan Normal University

Ting-Chen Yeh

National Taiwan Normal University

Christopher W. Johnson

Los Alamos National Laboratory

Yaochieh Chen

National Taiwan Normal University

Cheng-Horng Lin

Academia Sinica

Ya-Chuan Lai

National Applied Research Laboratories

Min-Hung Shih

Academia Sinica

\section{Research Article}

Keywords: vehicle traffic, metros, airports, industrial activity, traffic-roundabout, traffic flow, Human activities

Posted Date: July 26th, 2021

DOl: https://doi.org/10.21203/rs.3.rs-739878/v1

License: (a) (1) This work is licensed under a Creative Commons Attribution 4.0 International License. Read Full License 


\section{Abstract}

Examining continuous seismic data recorded by a dense broadband seismic network throughout Taipei shows for the first time, the nature of seismic noise in this highly populated metropolitan. Using 140 broadband stations in a $50 \mathrm{~km} \times 69 \mathrm{~km}$ area, three different recurring, strong noise signals characterized by dominant frequencies of $2-20 \mathrm{~Hz}, 0.25-1 \mathrm{~Hz}$, and $<0.2 \mathrm{~Hz}$ are explored. At frequencies of 2-20 Hz, the seismic noise exhibits daily and weekly variations, and a quiescence during the Chinese New Year holidays. The largest amplitude occurred at a station located only $400 \mathrm{~m}$ from a traffic-roundabout, one of the busiest intersections in Taipei, suggesting a possible correlation between large amplitude with traffic flow. The median daily amplitude for the $<0.2 \mathrm{~Hz}$ and $0.2-1.0 \mathrm{~Hz}$ frequency bands are mostly synchronized with high similarity between stations, indicating that the sources are persistent oceanic or atmospheric perturbations across a large area. The daily amplitude for the $>2 \mathrm{~Hz}$ band, however, is low, indicating a local source that changes on shorter length scales. Human activities responsible for the 2$40 \mathrm{~Hz}$ energy in the city, we discovered, are able to produce amplitudes approximately 2 to 1500 times larger than natural sources.

\section{Introduction}

Mounting evidence indicates that seismic noise in cities could be strong enough to contaminate the seismic catalogues used for the detection of earthquakes and tremors (e.g., Schmandt and Clayton, 2013; Ben-Zion et al., 2015; Inbal et al., 2018; Meng and Ben-Zion, 2018). A better understanding of noise produced by both natural and anthropogenic activities is thus crucial to improve the detection of small tectonic events in populated areas. Especially in urban areas with low seismic activity, ambient noise has become a key signal in modern seismology that utilizes seismic surveys for investigating underground structures and seismic microzonation (e.g., Shapiro and Campillp, 2004; Bonnefoy-Claudet et al., 2006; Lin et al., 2013; Li et al., 2016). Ambient noise in cities is driven by numerous human processes including vehicle traffic, metros, airports, and industrial activity (e.g., Groos et al., 2009; Díaz et al., 2017; Riahi et al., 2015). During the COVID-19 outbreak, a strong correlation between the magnitude of seismic noise and human mobility implies that seismic noise in dense urban environments provides a real-time estimate of population dynamics (Lecoq et al., 2020). A complete understanding of the spatial and temporal variations of urban induced ground motions is thus necessary for the successful utilization of seismic noise.

Seismic noises generated by cultural or natural origins have different frequency content and spatiotemporal characteristics (Gutenberg, 1958; Hasselmann, 1963; Asten, 1978; Asten, 1984; Peterson, 1993). They can be classified into two types: (1) microtremors (higher than $1 \mathrm{~Hz}$ ), signals that are mostly induced by human activity and that systematically exhibit daily and weekly variations (Hinzen, 2014; Riahi and Gerstoft, 2015; Boese et al., 2015; Green et al., 2017, Snover et al., 2020), or (2) microseisms (below $1 \mathrm{~Hz}$ ), signals mainly excited by oceanic gravity waves, which can be categorized into primary $(0.02-0.1 \mathrm{~Hz})$ and secondary $(0.1-0.5 \mathrm{~Hz})$ microseisms (Longuet-Higgin, 1950, Hasselmann, 1963; Peterson, 1993; Webb, 1998; Cessaro, 1994). With high levels of background noise found in urban areas, 
urban seismology has become an active research field due to the increasing number of seismic arrays located in cities (e.g., Bonnefoy-Claudet et al., 2006; Campillo, 2006; Groos and Ritter, 2009).

Taipei City is the political, economic, and cultural center of Taiwan and has a population of 2.7 million people. This metropolitan area is located in a Quaternary sediment-filled basin with low seismicity and composed of four geomorphological elements: the Western Foothills (WF), the Tatun volcanic area (TV), the Linkou Tableland (LT), and the Taipei Basin (TB) (Fig. 1C). The Tectonics and geology around the Taipei metropolitan area can be seen in Supplementary Information Text S1. The Formosa Array (FA), a dense broadband seismic array deployed in 2018 with 140 stations at approximately $5 \mathrm{~km}$ spacing, is used to investigate the geometry of the magma chamber beneath the Tatun volcanic area (Lin et al., 2021; Huang et al., 2021; Yeh et al., 2021). The FA also provides an excellent opportunity to study the characteristics and origin of urban seismic noise that is driven by numerous processes. This study is aimed at exploring the nature of ground vibration rhythm in Taipei metropolitan area and investigate what are the spatiotemporal characteristics and the possible origins of ambient noise in this highly populated city.

\section{Spectral Characteristics Of Seismic Noise In Taipei City}

A dense broadband seismic network with a $100 \mathrm{~Hz}$ sampling rate was deployed in the Taipei metropolitan area from 2017 to 2020 by the Institute of Earth Sciences of the Academia Sinica and the Taiwan Volcano Observatory at Tatun. The 140 seismic stations were divided into seven subareas (location shown in Fig. 1a), while the fifteen stations in the CT (abbreviation of "city") subarea located in the highly populated area near the Taipei Metro system (Fig. 1b) was first investigated. We used the vertical component of the continuous seismograms for 2 months from January 1 to February 28, 2019 to explore the characteristics of ambient noise. The data were preprocessed by removing the mean and trend, and deconvolving the instrument response. By calculating spectrograms for the two-month time-series using a 1-hr window with a 0.5 -hr overlap, we found a clear distinction in amplitude between day and night that occurs mainly in the range of $2-20 \mathrm{~Hz}$, as shown by the examples in Fig. 2. Station CT07 is located within 200 m of a metro station and main road, and CT08 and CT10 are located adjacent to a main road; all show the strongest spectral energy at approximately 2 and $10 \mathrm{~Hz}$. In contrast, station CT09 located $1270 \mathrm{~m}$ from the main road in a relatively remote area where only two buses operate each day, has a weaker amplitude between 2-20 Hz. A closer inspection of the CT09 daily time-series filtered between 2$40 \mathrm{~Hz}$ shows impulsive signals occurring between $6: 40$ am and 6:10 pm that coincide with the start and the end of the bus schedule in this area (Figure S1 in the supplementary file).

In the frequency band below $1 \mathrm{~Hz}$ (lower panels in Figs. 2a-d), the highest energy is observed from 0.2 to $0.6 \mathrm{~Hz}$, with different recurring patterns revealed when comparing the results with the 2-20 Hz frequency band. The $0.2-0.6 \mathrm{~Hz}$ frequency band shows longer recurrence times that range from 1.5 to 5 days. At frequencies $<0.2 \mathrm{~Hz}$, short-lived, frequently recurrent energy bursts are observed in the spectrograms. The energy bursts from February 12 to 18 (Figs. 2a-b) and January 12 to 18 (Figs. 2c-d) show similar arrivals for relatively higher-power spikes at different stations (red color). It was found that most of the high 
amplitude energy bursts (> $-90 \mathrm{~dB} / \mathrm{Hz}$ ) coincide with local and regional earthquakes (location please see Figure S2), as denoted by grey and blue arrows in the month-long spectrograms shown in Figure S3. The energy burst that persists relatively longer (> one hour) is found to correspond to a teleseismic event as denoted by orange arrow (the corresponding spectrogram can be seen in Figure S4).

The frequency characteristics of the seismic noise can be further studied through a spectral analysis on the continuous data over the study period of two month. Using Welch's technique (Welch, 1967), the power spectral density (PSD) is obtained for each station in Taipei city, as shown in Fig. 3, where the three separate frequency bands ( $>2 \mathrm{~Hz}, 0.2-1 \mathrm{~Hz}$, and $<0.2 \mathrm{~Hz}$ ) are denoted by horizontal bars in the bottom. The largest amplitude appears in the band of $2-20 \mathrm{~Hz}$ and smallest in $<0.2 \mathrm{~Hz}$. Note that the PDS distributions for $>2 \mathrm{~Hz}$ vary significantly between stations, while it remains highly similar for the $0.2-1 \mathrm{~Hz}$ and $<0.2 \mathrm{~Hz}$ bands. As revealed by the black arrows in Fig. 3, the highest peak occurs around $10 \mathrm{~Hz}$ (СТ01, СТ03, СТ06, СТ07, СТ08, СТ09, СТ12, СТ13, and СТ14) and around 4-5 Hz (СТ02, СТ04, СТ05, CT10, CT11, and CT16). The largest amplitude occurs at CT08, which is located $400 \mathrm{~m}$ from a trafficroundabout, one of the busiest intersections in Taipei, suggesting a possible correlation between large amplitude with vehicle traffic. The smallest amplitudes are observed at CT09, CT13, and CT16 that are located near Western Foothills and consistent with the dark blue stations in Fig. 1b. Comparing with other CT stations, these 3 quiet stations happen to be the farthest from metro lines (> $1.5 \mathrm{~km})$, implying that they are relatively remote from the core population of Taipei city.

The temporal behavior in the 2-40 Hz bands reveals a stronger variation when comparing with $<1 \mathrm{~Hz}$ frequency. This can be seen by the difference between the grey and blue lines in Fig. 3. There exists a general trend of slightly greater amplitude in day-time, as revealed by the grey lines that are higher than blue lines in Fig. 3, mainly in the range of $2-40 \mathrm{~Hz}$. The difference of spectral amplitude between day and night is as large as a factor of 1.3-1.5 at CT09 and CT13 stations for approximately $12-40 \mathrm{~Hz}$.

\section{Similarity Of Ambient Noise Across City Stations}

A cross-correlation analysis of each 60-s of signal was undertaken using all CT station pairs, for 4 different frequency bands of $<0.2 \mathrm{~Hz}, 0.2-1 \mathrm{~Hz}, 1-3 \mathrm{~Hz}$, and $10-20 \mathrm{~Hz}$. Here the 2-20 Hz band is separated into a 1-3 Hz band and a $10-20 \mathrm{~Hz}$ band, given that the energy concentration above $2 \mathrm{~Hz}$ is usually segmented into these two frequency bands (Fig. 2). The top three highest cross-correlation coefficients $(c c c)$ for the different frequency bands were averaged and smoothed every three hours and are displayed as a function of time in Fig. 4. The population of the three highest $c c c$ values across the station-pairs is found to be centered at $c c c=0.88$ for frequency of $<0.2 \mathrm{~Hz}, c c c=0.81$ for $0.2-1 \mathrm{~Hz}$, and $c c c=0.54$ for both the $1-3 \mathrm{~Hz}$ and $10-20 \mathrm{~Hz}$ bands. There exists a significant difference in waveform similarity for noise with frequencies lower and higher than $1 \mathrm{~Hz}$. The higher similarity between stations at frequencies lower than $1 \mathrm{~Hz}$ indicates a strong influence over a large area, whereas the low similarity of seismic signals at frequencies higher than $1 \mathrm{~Hz}$ however, may represent a local source that changes on shorter length scales. 
We also found that the significant coherence (>0.9) occurs at low frequencies below $0.1 \mathrm{~Hz}$ between stations even at a wide spacing of $>15 \mathrm{~km}$. At stations where weaker traffic signals are observed such as the quiet station pairs CT04 and CT16 in Fig. 5a-b, the coherence is very high $(\sim 1)$ near $0.1 \mathrm{~Hz}$ and falls off rapidly below 0.25 at higher frequency. The coherence appears to gradually increase with frequency from $20 \mathrm{~Hz}$. At stations where traffic signals are strong (СТ06 and СT07 stations), the coherence also reaches $\sim 1$ below $0.1 \mathrm{~Hz}$, as shown in Fig. $5 \mathrm{c}-\mathrm{d}$. At higher frequencies $(>1 \mathrm{~Hz})$, however, the coherence remains lower than 0.3. Different station pairs reveal similar trend of (1) low coherence at $>1 \mathrm{~Hz}$ and (2) high coherence at $<0.2 \mathrm{~Hz}$. At frequency above $1 \mathrm{~Hz}$, the coherence reveals significant variation in time. During rush hours, the coherence tends to be higher than that during the late-night hours, which is likely due to the similar traffic rhythm in the city, especially from high traffic intersections producing ground vibrations.

\section{Temporal Variation Of The Seismic Amplitude In The City}

To better capture the temporal variation of ambient noise in the city, the median value of daily amplitude is displayed in Fig. 6. The unfiltered waveforms show a common decrease of amplitude over the weekends and during the Chinese New Year from February 2 to 10. Based on the magnitude and temporal patterns of the median daily amplitude, the fifteen CT stations can be categorized into three groups (A-C). In each group (indicated by different colors in the lower panel of Fig. 6), the stations show very similar behavior in time. The largest amplitudes occur at station CT10 (Group A) and are consistent with the maximum amplitude shown in Fig. 1b. Except for the Chinese New Year holiday, this station has a large decrease in amplitude each Saturday, while the amplitude during the weekdays varies little. Stations СT02, СT05, СT06, СТ07, СТ08, СТ11, СТ12, and СT14 comprise Group B and show a similar temporal pattern that differs from that of Group A. Group B has lower amplitudes and the difference between the minimum and maximum amplitudes is relatively small, even during the weekends. Stations CT01, CT03, CT04, CT09, CT13, and CT16 make up Group C and have the lowest observed amplitudes. Unlike the weekend quiescence seen in Groups A and B, the amplitude variations in Group C are less regular and are not consistent during the weekends. While a decrease in amplitude does occur during the Chinese New Year (from February 2 to 10), as can be seen in Groups A and B, it is not obvious in Group C, suggesting that the source of energy responsible for Group $C$ might be different than for Groups A-B.

Comparing the temporal amplitude variation in different frequency bands in Fig. 7 (green lines for CT stations), the temporal trends in Groups A and B are similar to that of the 2-20 Hz trend (Fig. 7c), whereas Group $C$ shows similar temporal behavior to $0.25-1.0 \mathrm{~Hz}$ band (Fig. $7 \mathrm{~b}$ ). We thus argue that the temporal distribution of seismic noise in the city is likely frequency dependent. In Groups $A$ and $B$, where the stations are largely influenced by human activity, the energy associated with $2-20 \mathrm{~Hz}$ band is dominant. In Group C, the stations are farther from the city center where there is generally less traffic and the contribution of low-frequency energy below $1 \mathrm{~Hz}$ is more dominant. Among the fifteen CT stations, CT10 and СT09 show the highest and lowest median daily amplitudes, respectively. The quietest station, CT09, is located $1270 \mathrm{~m}$ from the main road and $2790 \mathrm{~m}$ from the nearest metro station. In contrast, station CT10 is located only $136 \mathrm{~m}$ from the main road and $1010 \mathrm{~m}$ from the nearest metro station. This 
indicates a possible relationship between the median shaking level and the distance from the main road or metro station that contributes to the seismic noise in the $2-20 \mathrm{~Hz}$ frequency band.

\section{Temporal Variation Of The Seismic Amplitude In The Metropolitan Area}

To understand how the temporal patterns in the three frequency bands vary spatially, the median daily amplitude at all 140 stations was calculated and displayed in Fig. 7. At frequencies below $0.2 \mathrm{~Hz}$, the temporal variation in six subareas outside Taipei City are consistent and have a small range of amplitude from $2.1 \times 10^{-7}$ to $2.5 \times 10^{-6} \mathrm{~m} / \mathrm{s}$ (denoted by the vertical blue bar on the $y$-axis in Fig. $7 \mathrm{a}$, which is the range of the initial amplitude in the examined time-series). However, the CT stations in the city show initial amplitudes between $1.3 \times 10^{-8}$ and $3.5 \times 10^{-8} \mathrm{~m} / \mathrm{s}$, which is approximately an order of magnitude smaller than the other six subareas. For the $0.25-1.0 \mathrm{~Hz}$ frequency band, a similar initial amplitude range of $1.1 \times 10^{-7}$ to $4.6 \times 10^{-6} \mathrm{~m} / \mathrm{s}$ is observed, but in this case the largest amplitude is observed at the CT stations (Fig. 7b). We suspect that the effect of basin resonance may play a role, which will be discussed in next section.

The temporal variation is consistent for stations in different subareas throughout the range of amplitudes. Note that the median daily amplitude for the $<0.2 \mathrm{~Hz}$ and $0.25-1.0 \mathrm{~Hz}$ frequency bands are mostly synchronized (Figs. 7a-b), suggesting the sources are a persistent disturbance distributed over a large area. The higher frequency band of $2-20 \mathrm{~Hz}$ reveals higher amplitudes at the CT stations with values ranging from $5.5 \times 10^{-7}$ to $1.0 \times 10^{-5} \mathrm{~m} / \mathrm{s}$ (blue vertical bar in Fig. 7c). The temporal variation at the CT stations indicates the influence of human activity with the lowest amplitudes observed consistently during the weekends and the Chinese New Year holidays (grey area in Fig. 7c). The median amplitudes for the stations outside the city exhibit a surprisingly similar time pattern, yet with reduced amplitudes, suggesting a common driving force. We found that only the CT stations show significant frequency dependency; the vibration at $2-20 \mathrm{~Hz}$ reveals widely different temporal behavior compared with that at $0.25-1 \mathrm{~Hz}$ and $<0.2 \mathrm{~Hz}$ frequency bands (green curves in Fig. 7).

As shown in Figure S5, the spectrograms from sample stations in each subarea confirm that the higher frequency band is consistent with energy concentrating above $2 \mathrm{~Hz}$, yet is weaker than observed in the CT subarea and sometimes lacks a weekly variation (Figure S5 d-f). At the lower frequency band below $1 \mathrm{~Hz}$, there is a clear boundary at $0.25 \mathrm{~Hz}$ for all stations outside the city (Figure S5), whereas in the city (CT stations) the boundary is at $0.2 \mathrm{~Hz}$ (Fig. 2). Note that at the stations outside the city, the amplitude of the lower $(<1 \mathrm{~Hz})$ frequency band is commonly found to be much stronger than the higher frequency bands $(>2 \mathrm{~Hz}$ ). These long period signals are very different from what is observed in the CT stations, where the anthropogenic noise at $2-20 \mathrm{~Hz}$ remains strongest near the main roads and metro rail lines.

\section{Seismic Site Effects Due To Thick Basin Sediments}


The amplitude of land-recorded, secondary microseismic noise is found to be controlled by the sediment thickness below the source region and the source location relative to the local ocean depth (Gualtieri et al., 2013, 2015). At the top of the Taipei Basin, there is an approximately 120 -m thick Quaternary sedimentary layer that is characterized by a P-wave velocity of $0.45-2.2 \mathrm{~km} / \mathrm{s}$ and an S-wave velocity of 0.17 to $0.88 \mathrm{~km} / \mathrm{s}$ (Lee et al., 2008). This Sungshan Formation has been recognized to be responsible for the amplification of seismic waves during earthquakes (e.g., Chen, 2003; Lee et al., 2008). The depth distribution of the Shungshan formation is shown by Fig. 1b, showing a deepest part located to the NW of the basin. The anomalous thickness of the soft sediment in the basin (CT subarea) leads to a dominant frequency of $0.5 \mathrm{~Hz}$ (Lin et al., 2014), which provides an alternative interpretation for the large amplitude of seismic waves in the 0.25-1 Hz frequency band (green lines in Fig. 7b). Based on the microtremor H/V measurements, the fundamental frequency in the Taipei Basin is approximately $0.5 \mathrm{~Hz}$, which is lower than those in sites on the plain and hill that are characterized by frequencies higher than 1 $\mathrm{Hz}$ (Liu et al., 1999). The higher amplitude at 0.25-1 Hz events at CT stations could be a result of the resonance frequency of the Sungshan Formation.

\section{The Regional Dependence Of The Seismic Amplitude During Typhoons}

It is also possible that the strong wind restricted to the surface has impact on the city center due to the shaking of the buildings (Ward and Crawford, 1966). To understand the seismic response due to wind disturbance, the waveform, spectrum, and hourly median amplitude during a strong typhoon, the Likema typhoon that occurred from August 7-9, is now examined. As shown in Fig. 8, the typhoon land warning was issued at 5:30 pm on August 7, whereas early in the morning there was a M6.2 earthquake offshore of the northeast of Taiwan near Yilan County (sharp peak in upper panel of Fig. 8a). A maximum wind velocity of $21.1 \mathrm{~m} / \mathrm{s}$ was recorded at the weather station in Taipei City at 7:00 pm on August 9. The corresponding spectral behavior reveals a peak near $0.2 \mathrm{~Hz}$ and a frequency range of 0.1 to $1 \mathrm{~Hz}$ (Figs. 8c-d). On August 8, the spectra present a more complicated pattern with two peaks at $0.03-0.06 \mathrm{~Hz}$ and $0.2-1 \mathrm{~Hz}$, the largest amplitude being recorded at the CT stations (Fig. 8b). Given that the typhoon did not arrive until the evening of August 8, the spectral behavior for this day may combine the effects from the M6.2 earthquake, anthropogenic noise, and the growing wind field.

The spatial distribution of the maximum amplitude in the Formosa Array is shown in Figure S6. The maximum hourly-averaged seismic energy is found to occur along the coast of the LK and VO subareas and the port of Keelung, which remained the same at different hours of a day. Comparing the seismic data with precipitation and wind velocity at 9 am and $10 \mathrm{am}$, it was found that the maximum precipitation is highly variable over time without clear correlation with seismic data (Figures S6c and f). However, the hourly averaged wind speed is persistent with time and is concentrated at two locations on the northern coast (dark red and orange triangles in Figures S6b and e), which is more consistent with the seismic data. Note that the spatial correlation between strong winds, high rainfall intensity, and the largest seismic amplitude in the $0.25-1 \mathrm{~Hz}$ is not clear, which could be due to a lack of weather stations in 
the LK subarea. As the typhoon originally developed offshore of Taiwan to the east, the impact of terrain on typhoon circulation may play an important role in generating the enhanced amplitude along the coastal stations in the VO and LK subareas. The basin area (CT) however, was not found to experience the largest seismic amplitude at $0.25-1 \mathrm{~Hz}$ during the strong typhoon. We argue that during typhoons, the 0.25-1 Hz seismic waves are mainly generated by strong winds. Without typhoons, the frequency of approximately $0.5 \mathrm{~Hz}$ could be amplified due to the presence of thick and soft sediments in the basin. The largest noise amplitude in the $0.25-1 \mathrm{~Hz}$ range observed in the $\mathrm{CT}$ subarea illustrated in Fig. $7 \mathrm{~b}$, is interpreted by the ambient noise induced resonance in deep sedimentary basin.

\section{Possible Origin Of The Seismic Noise}

The major source of vibration excitations for a moving train is the rail-wheel-body interaction, and Hajek et al. (2006) reported that separate frequency ranges of $0.8-4 \mathrm{~Hz}$ and $8-15 \mathrm{~Hz}$ are responsible for trainbody skipping from pavement unevenness and axle hop movement, respectively. Mhanna et al. (2012) further demonstrated that the main frequency can be switched between $2 \mathrm{~Hz}$ and $10 \mathrm{~Hz}$ when the geometry of the speed reducer and suspension system changes. Using microelectromechanical system (MEMS) sensors to record the vibration of moving vehicles in Taipei City, we confirmed that a moving metro train, bus, and truck exhibit dominant frequencies of 2-10 Hz. Therefore, the energy concentrations at approximately $2 \mathrm{~Hz}$ and $10 \mathrm{~Hz}$ are interpreted as city traffic induced vibrations.

Natural sources contribute to the lower frequency band below $1 \mathrm{~Hz}$, and these sometimes overlap with anthropogenic signals (Bonnefoy-Claudet et al., 2006; Nishda, 2017). Oceanic infragravity waves have long been recognized as the most likely source of seismic free oscillation. Atmospheric disturbances produce a pressure source at the seafloor, and the induced oceanic infragravity waves can excite a very long period seismic hum (frequency $<0.02 \mathrm{~Hz}$ ). The nonlinear interactions among wind waves are also able to produce ocean infragravity waves (Webb et al., 1991; Tanimoto, 2005). Since the behavior of oceanic infragravity waves is depth dependent and exhibits a strong coupling with seabed topography, both oceanic and atmospheric forcing is likely responsible for the observed microseisms in Taipei. In the present observation of temporal variation over the seismic stations, the $<0.2 \mathrm{~Hz}$ band demonstrates a stronger amplitude near the shore, indicating that the seismic waves in this frequency band are excited more efficiently. The ocean broadband seismometers (OBS) deployed offshore of Taiwan have detected typhoon-excited microseisms at 0.085-0.2 Hz and 0.15-0.5 Hz (Chi et al., 2010; Lin et al., 2014), suggesting that the driving force for $<1 \mathrm{~Hz}$ seismic signals is more closely associated with ocean waves. The possible relationship with air pressure, average wind speed, and wind velocity was also examined. Five weather stations in the Taipei metropolitan area were selected for comparison with the nearest FA station. The weather observations (daily average air pressure, wind velocity, and wind gust for maximum speed) were cross-correlated with the seismic noise daily median amplitude for the three different bands. As shown in Table S1, among the five station sets, the largest cross-correlation coefficient (ccc) is found at KM26 and the Suao coastal station, where the $c c c$ between seismic noise and wind gusts reaches 0.62 for the $<0.2 \mathrm{~Hz}$ frequency band and 0.59 for the $0.25-1 \mathrm{~Hz}$ band. The lowest $c c c$ values are observed at the Wufenstan and Banqiao weather stations, which are located away from the coast. At the three 
weather stations on or near the coast, the higher $c c c$ can be seen (1) at the lowest frequency band of $<0.2$ $\mathrm{Hz}$, and (2) for wind gusts (KM26 versus Suao and KM12 versus Yilan) and wind velocities (LK01 versus Tamsui). The lower $c c c$ at the inland stations suggests that the coastal areas may provide an environment that allows for a more direct association between seismic noise and changing wind conditions. Such association, however, is only modest due to the generally lower ccc of $<0.7$.

\section{Conclusion}

Continuous data recorded at the 140 stations located in the Taipei metropolitan area provide a unique opportunity to demonstrate the spatiotemporal characteristics of weak ground motion in an urban area. We find three types of seismic noise that are characterized by dominant frequencies of $>2 \mathrm{~Hz}, 0.25-1 \mathrm{~Hz}$, and $<0.2 \mathrm{~Hz}$. At stations in the city, the energy in the $2-20 \mathrm{~Hz}$ frequency band is dominant with a relatively large amplitude. The amplitude is lowest on the weekends and during the Chinese New Year holidays, suggesting a strong association with human activities. In the city, a strong variation appears in amplitude and temporal patterns, indicating that the traffic-induced vibration is localized and the effect varies from station to station.

In the relatively remote areas on the hill and near the coast, the human-induced ground shaking is weaker and the natural sources, such as oceanic and meteorological effects with frequency content $<1 \mathrm{~Hz}$, appear to modulate the observed temporal variation. In the two-month study period from January 1 to February 28,2019 , the daily median amplitude for the $<0.2 \mathrm{~Hz}$ and $0.25-1 \mathrm{~Hz}$ frequency bands reveal surprisingly consistent patterns at all stations, indicating a common driving force. The largest amplitudes at the beginning of the time-series for $2-10 \mathrm{~Hz}, 0.25-1 \mathrm{~Hz}$, and $<0.2 \mathrm{~Hz}$ were $1.0 \times 10^{-5}, 2.5 \times 10^{-6}$,

and $4.5 \times 10^{-6} \mathrm{~m} / \mathrm{s}$, respectively. Thus, from maximum amplitude, anthropogenic activities are able to produce weak ground shaking that is 2.2-4.0 times greater than meteorological sources. From all amplitudes from various stations, such ratio can range from 2 to 1500 . Naturally occurring noise from oceanic and atmospheric sources primarily contribute to the lower frequency band $(<1 \mathrm{~Hz})$. We found the time-series for the $<0.2 \mathrm{~Hz}$ and $0.25-1 \mathrm{~Hz}$ seismic data show higher similarity with the recorded wind velocity. Special attention was given to the high amplitudes of $0.1-1 \mathrm{~Hz}$ observed at city stations in the Taipei Basin. Given that the resonant frequency of the sedimentary basin (an approximately 120-m thick soft sediment) was centered around $0.5 \mathrm{~Hz}$, it is argued that the regional dependency of amplitude for the $0.25-1 \mathrm{~Hz}$ energy is likely controlled by the site effect.

\section{Declarations}

\section{Acknowledgements}

This work is supported through Taiwan MOST grants MOST 108-2116-M-003 -006 -MY3. CWJ acknowledges institutional support (Laboratory Directed Research and Development) at Los Alamos National Lab. We wish to thank Wen-Tzong Liang, Jyun-Yen Huang, Ban-Yuan Kao for their valuable 
comments. We would like to thank Uni-edit (www.uni-edit.net) for editing and proofreading this manuscript.

\section{Authors' contributions}

Kate Huihsuan Chen designed the research and wrote the manuscript. Christopher W. Johnson contributed to the interpretation of the results. Ting-Chen Yeh and Yaochieh Chen contributed to data analysis. Cheng-Horng Lin, Ya-Chuan Lai, and Min-Hung Shih took charge of the installation and maintenance of the seismic data of Formosa Array. All authors read and approved the final manuscript.

\section{Additional Information}

We confirm that there are no known conflicts of interest associated with this publication and there has been no significant financial support for this work that could have influenced its outcome.

\section{References}

Asten, M. W. (1978). Geological control of the three-component spectra of Rayleigh-wave microseisms. Bulletin of the Seismological Society of America, 68:1623-1636.

Asten, M. W., Henstridge, J. D. (1984). Arrays estimators and the use of microseisms for reconnaissance of sedimentary basins. Geophysics, 49:1828-1837

Ben-Zion, Y., Vernon, F. L., Ozakin, Y., Zigone, D., Ross, Z. E., Meng, H., White, M., Reyes, J., Hollis, D., \& Barklage, M. (2015). Basic data features and results from a spatially dense seismic array on the San Jacinto fault zone. Geophysical Journal International, 202(1), 1-11. https://doi.org/10.1093/gji/ggv142

Boese, C. M., Wotherspoon, L., Alvarez, M., \& Malin, P. (2015). Analysis of anthropogenic and natural noise from multilevel borehole seismometers in an urban environment, Auckland, New Zealand. Bulletin of the Seismological Society of America, 105(1), 285-299. https://doi.org/10.1785/0120130288

Bonnefoy-Claudet, S., Cotton, F., \& Bard, P. Y. (2006). The nature of noise wavefield and its applications for site effects studies. A literature review. Earth-Science Reviews, 79(3-4), 205-227. https://doi.org/10.1016/j.earscirev.2006.07.004

Campillo, M. (2006). Phase and correlation in "random" seismic fields and the reconstruction of the green function. Pure and Applied Geophysics, 163(2-3), 475-502. https://doi.org/10.1007/s00024-005-0032-8

Cessaro, R. K. (1994). Sources of primary and secondary microseisms, Bulletin of the Seismological Society of America, 84 (1), 142-148.

Chen, K. C. (2003). Strong ground motion and damage in the Taipei basin from the Moho reflected seismic waves during the March 31, 2002, Hualien, Taiwan earthquake. Geophysical Research Letters, 30, 1551. https://doi.org/10.1029/2003GL017193 
Chen, W. F., and L. S. Teng (1990). Depositional environment of Quaternary deposits of the Linkou Tableland, northwestern Taiwan, Proceedings of Geological Society of China, 33, 39-63.

Chi, W. C., Chen, W. J., Kuo, B. Y, \& Dolenc, D. (2010). Seismic monitoring of western Pacific typhoons, Marine Geophysical Research, 31, 239-251. https://doi.org/10.1007/s11001-010-9105-x

Díaz, J., Ruiz, M., Sánchez-Pastor, P. S., and Romero, P. (2017). Urban seismology: on the origin of earth vibrations within a city. Scientific Reports. 7:15296. doi: 10.1038/s41598-017-15499-y

Green, D. N., Bastow, I. D., Dashwood, B., \& Nippress, S. E. J. (2017). Characterizing broadband seismic noise in Central London. Seismological Research Letters, 88(1), 113-124.

https://doi.org/10.1785/0220160128

Groos, J. C., \& Ritter, J. R. R. (2009). Time domain classification and quantification of seismic noise in an urban environment. Geophysical Journal International, 179(2), 1213-

1231. https://doi.org/10.1111/j.1365-246X.2009.04343.x

Gualtieri, L., Stutzmann, E., Capdeville, Y., Ardhuin, F., Schimmel, M., Mangeney, A., \& Morelli, A. (2013). Modelling secondary microseismic noise by normal mode summation. Geophysical Journal International, 193(3), 1732-1745.

Gualtieri, L., Stutzmann, É., Capdeville, Y., Farra, V., Mangeney, A., \& Morelli, A. (2015). On the shaping factors of the secondary microseismic wavefield. Journal of Geophysical Research: Solid Earth, 120(9), 6241-6262.

Gutenberg, B. (1947). Microseisms and weather forecasting. Journal of Atmospheric Sciences, 4(1), 2128.

Hajek, J. J., Blaney, C. T., \& Hein, D. K. (2006). Mitigation of highway traffic-induced vibration. TAC/ATC 2006 - 2006 Annual Conference and Exhibition of the Transportation Association of Canada:

Transportation Without Boundaries, 1-13.

Hasselmann, K. (1963). A statistical analysis of the generation of microseisms. Reviews of Geophysics, 1(2), 177-210.

Hinzen, K. G. (2014). Subway-induced vibrations in cologne cathedral. Seismological Research Letters, 85(3), 631-638. https://doi.org/10.1785/0220140003

Ho, C. S. (1974). The Taipei fault and related structural features in northern Taiwan, Proceedings of Geological Society of China, 17,95-109.

Hsiao, L. Y., Lin, K. A., Huang, S. T. and Teng, L. S. (1998). Structural characteristics of the southern Taiwan-Sinzi folded zone. Pertroleum Geology of Taiwan, 32,133-153. (in Chinese) 
Inbal, A., Cristea-Platon, T., Ampuero, J. P., Hillers, G., Agnew, D., \& Hough, S. E. (2018). Sources of longrange anthropogenic noise in southern California and implications for tectonic tremor detection. Bulletin of the Seismological Society of America, 108(6), 3511-3527. https://doi.org/10.1785/0120180130

Lecocq, T., Hicks, S., Van Noten, K., et al. (2020), Global quieting of high-frequency seismic noise due to COVID-19 pandemic lockdown measures. Science, 369, 1338-

1343, https://doi.org/10.1126/science.abd2438.

Lee, S. J., Chen, H. W., Huang, B. S. (2008). Simulations of strong ground motion and 3D amplification effect in the Taipei basin by using a composite grid finite-difference method, Bulletin of the Seismological Society of America, 98(3), 1229-1242.

Li, C., Yao, H., Fang, H., Huang, X., Wan, K., Zhang, H., \& Wang, K. (2016). 3D near-surface shear-wave velocity structure from ambient-noise tomography and borehole data in the Hefei urban area, China. Seismological Research Letters, 87(4), 882-892.

Lin, J. Y., Lee, T. C., Hsieh, H. A., Chen, Y. F., Lin, Y. C., Lee, H. H., \& Wen, Y. Y. (2014), A Study of Microseisms Induced by Typhoon Nanmadol Using Ocean-Bottom Seismometers. Bulletin of the Seismological Society of America, 104, 5, oi: 10.1785/0120130237.

Liu, K. S., Shin, T. C., \&Tsai, Y. B. (1999). A free-field strong motion network in Taiwan: TSMIP. Terrestrial Atmospheric and Oceanic Sciences, 10(2), 377-396.

Longuet-Higgins, M. S. (1950). A theory of the origin of microseisms. Philosophical Transactions of the Royal Society of London. Series A, Mathematical and Physical Sciences, 243(857), 1-35.

Meng, H., \& Ben-Zion, Y. (2018). Characteristics of Airplanes and Helicopters Recorded by a Dense Seismic Array Near Anza California. Journal of Geophysical Research: Solid Earth, 123(6), 4783-4797. https://doi.org/10.1029/2017JB015240

Mhanna, M., Sadek, M., \& Shahrour, I. (2012). Numerical modeling of traffic-induced ground vibration. Computers and Geotechnics, 39, 116-123. https://doi.org/10.1016/j.compgeo.2011.07.005

Nishida, K. (2017). Review Ambient seismic wave field. The Proceedings of the Japan Academy, 93(7), 423-448. https://www.jstage.jst.go.jp/article/pjab/93/7/93_PJA9307B-01/_article

Peterson, J. (1993). Observations and modeling of seismic background noise, U.S.G.S, Open File Report, 93-322, $95 \mathrm{p}$.

Riahi, N., \& Gerstoft, P. (2015). The seismic traffic footprint: Tracking trains, aircraft, and cars seismically. Geophysical Research Letters, 42(8), 2674-2681. https://doi.org/10.1002/2015GL063558

Schmandt, B., \& Clayton, R. W. (2013). Analysis of teleseismic P waves with a 5200-station array in Long Beach, California: Evidence for an abrupt boundary to Inner Borderland rifting. Journal of Geophysical 
Research: Solid Earth, 118(10), 5320-5338. https://doi.org/10.1002/jgrb.50370

Shapiro, N. M. and Campillo. M. (2004), Emergence of broadband Rayleigh waves from correlations of the ambient seismic noise. Geophysical Research Letters, 31, L07614, https://doi.org/10.1029/2004GL019491.

Snover, D., Johnson, C.W., Bianco, M.J., Gerstoft, P. (2020). Deep clustering to identify sources of urban seismic noise in Long Beach, CA. Seismological Research Letters, 1-12, doi: 10.1785/0220200164.

Suppe, J. (1984). Kinematics of arc-continent collision, flipping of subduction, and back-arc spreading near Taiwan, Memoir of the Geological Society of China, 6,21-34.

Tanimoto, T. (2005). The oceanic excitation hypothesis for the continuous oscillations of the Earth. Geophysical Journal International, 160(1), 276-288. https://doi.org/10.1111/j.1365-246X.2004.02484.x

Teng, L.S., (1996). Extensional collapse of the northern Taiwan mountain belt. Geology, 24, 949-952.

Teng, L. S., Lee, C. T., Peng, C. H., Chen, W. F., Chu, C. J. (2001). Origin and geological evolution of the Taipei basin, northern Taiwan, Western Pacific Earth Sciences, 1(2), 115-142.

Wang, C. Y., Lee, Y. H., Ger, M. L., Chen, Y. L. (2004). Investigating subsurface structures and P- and S-wave velocities in the Taipei Basin. Terrestrial, Atmospheric and Oceanic Sciences, 15(4), 609-627.

Ward, H. S., \& Crawford, R. (1966). Wind-induced vibrations and building modes. Bulletin of the Seismological Society of America, 56(4), 793-813.

Webb, S. C., Zhang, X., \& Crawford, W. (1991). Infragravity waves in the deep ocean. Journal of Geophysical Research, 96(C2), 2723-2736. https://doi.org/10.1029/90JC02212

Welch, P.D. (1967). The use of fast fourier transform for the estimation of power spectra: a method based on time-averaging over short, modified periodograms, IEEE Trans. Audio Electroacoust., 15(2), 70-73.

\section{Figures}


(a)

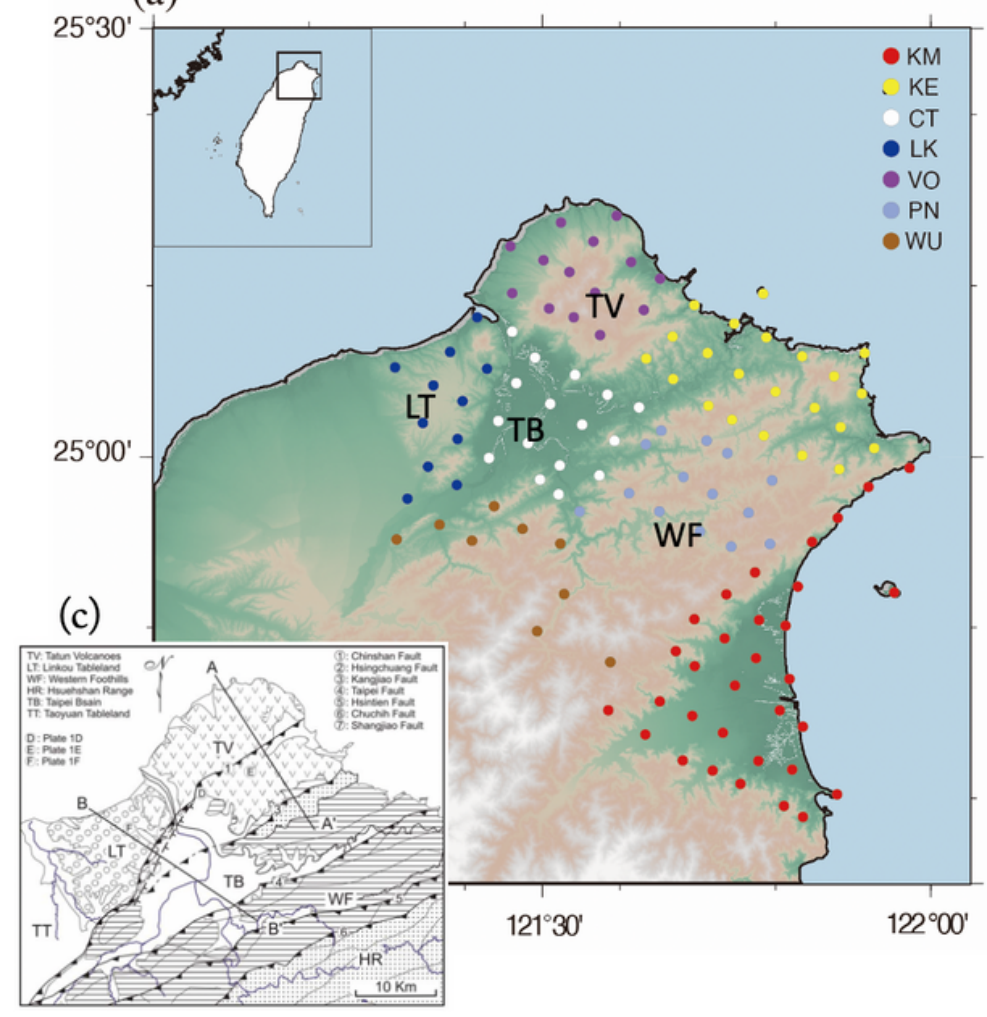

(b)

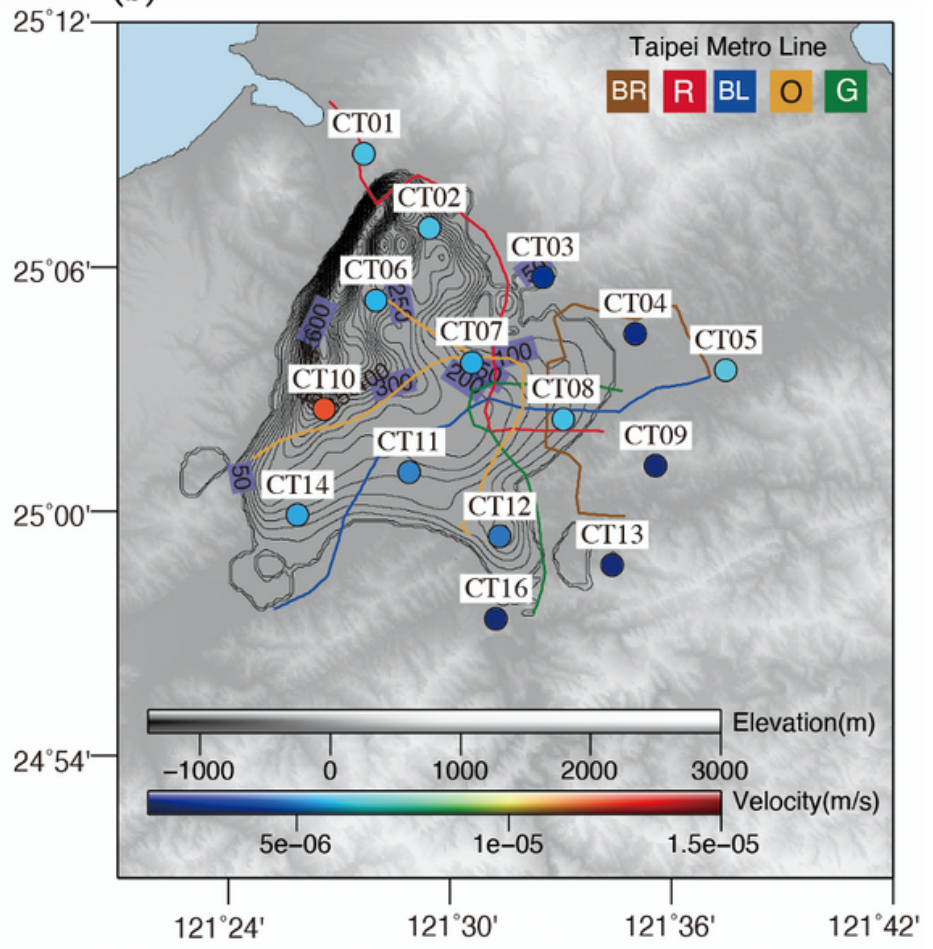

Figure 1

(a) Map of northern Taiwan showing the 140 broadband stations in the Formosa Array (FA) located in the Taipei metropolitan area. The stations are divided into seven subareas shown with the different colors and abbreviation for each. The inset map shows the location in Taiwan. WF: the Western Foothills; TV: the Tatun volcanoic area; LT: the Linkou Tableland; TB: the Taipei Basin. (b) The fifteen CT stations located in the main city of Taipei, with each station color-coded according to the median value of the daily amplitude of the background seismic noise. The colored lines show the Taipei metro system route map with the corresponding color indicating the metro line abbreviation. The contour denotes the Tertiary basement depth contours of the Taipei basin by Wang et al. (2004). (c) Geological setting of Taipei basin from Figure 2 in Teng et al. (2001). 
(a)
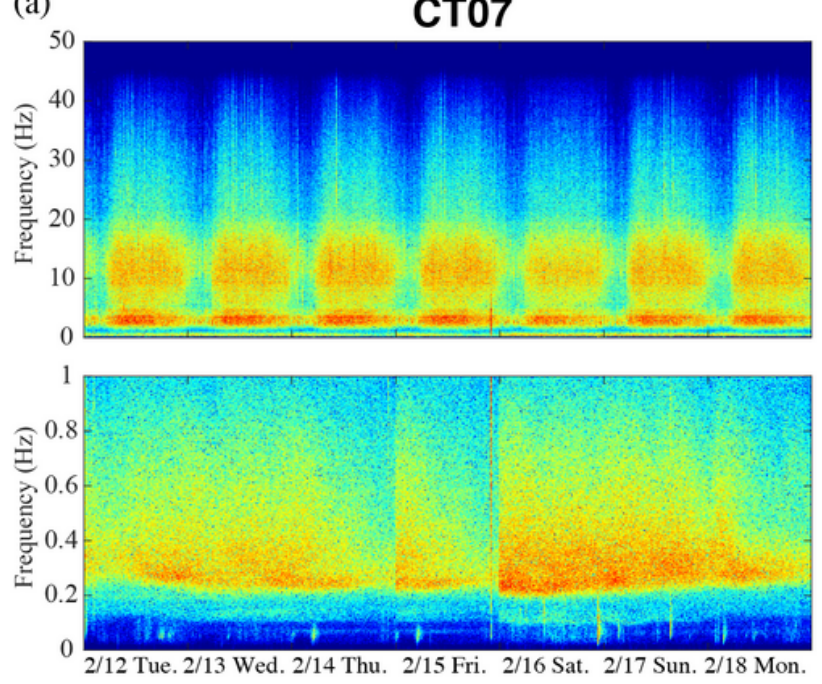

(c)
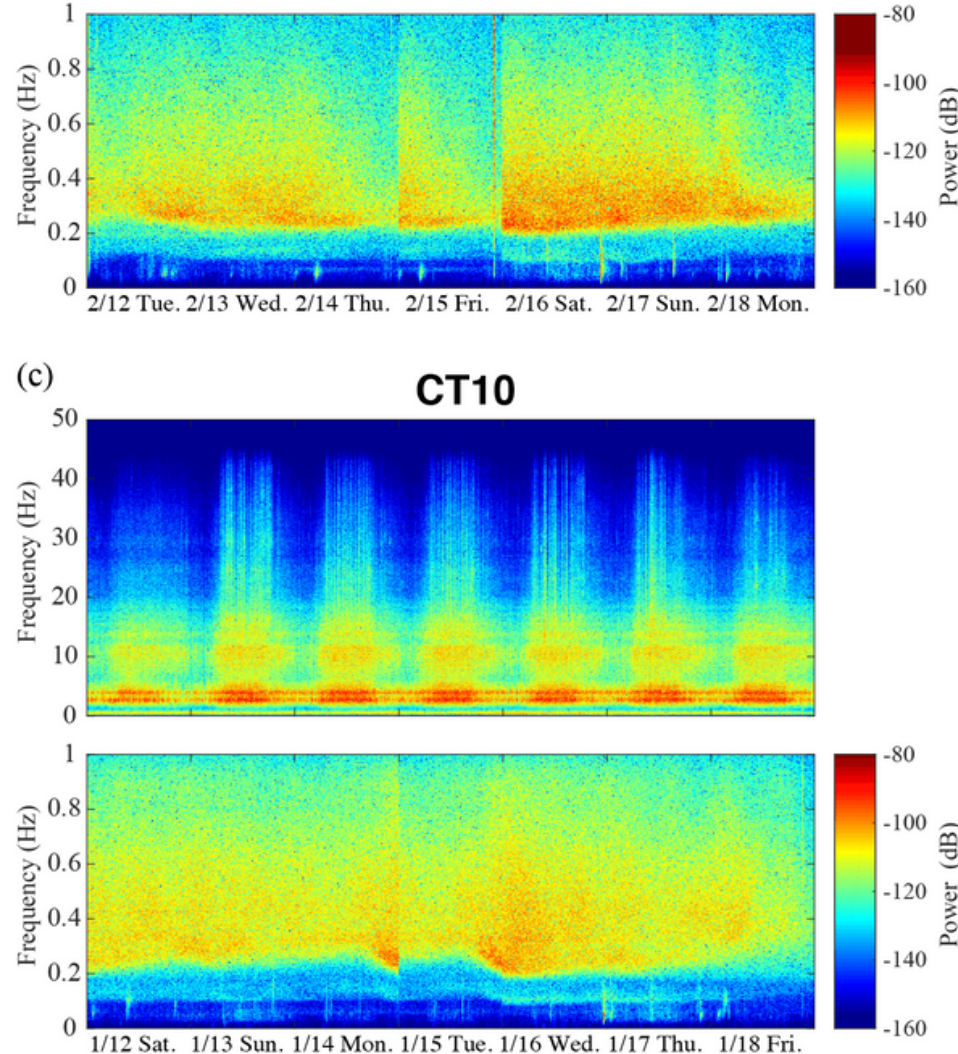

(b)
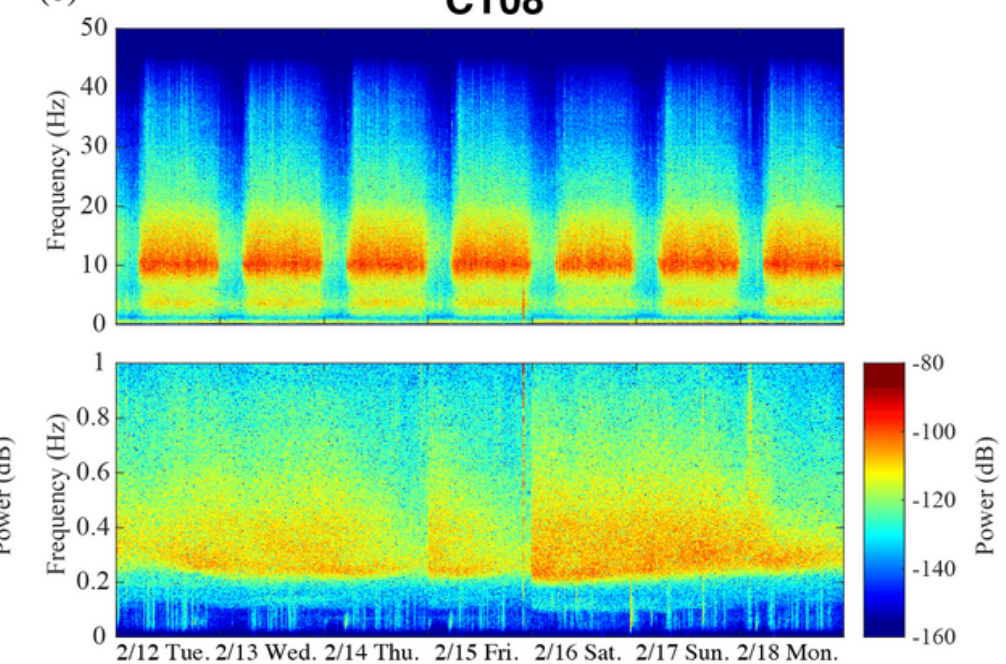

(d)
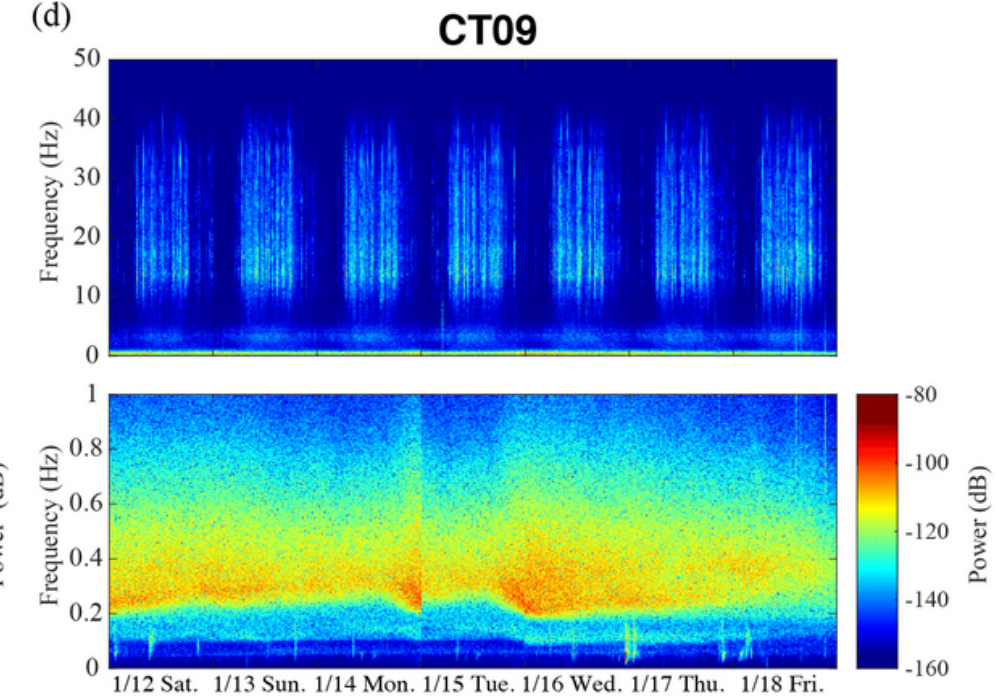

Figure 2

Spectrograms of the vertical seismic data for four stations from the CT subarea. Data for Station (a) CT07 and (b) CT08 are for the period of February 12 to 18, 2019, and (c) and (d) for the period of January 12 to 18 in the same year. In each figure, the upper panel shows the frequency range from $0-50 \mathrm{~Hz}$ and the lower panel only shows low frequencies, below $1 \mathrm{~Hz}$. 

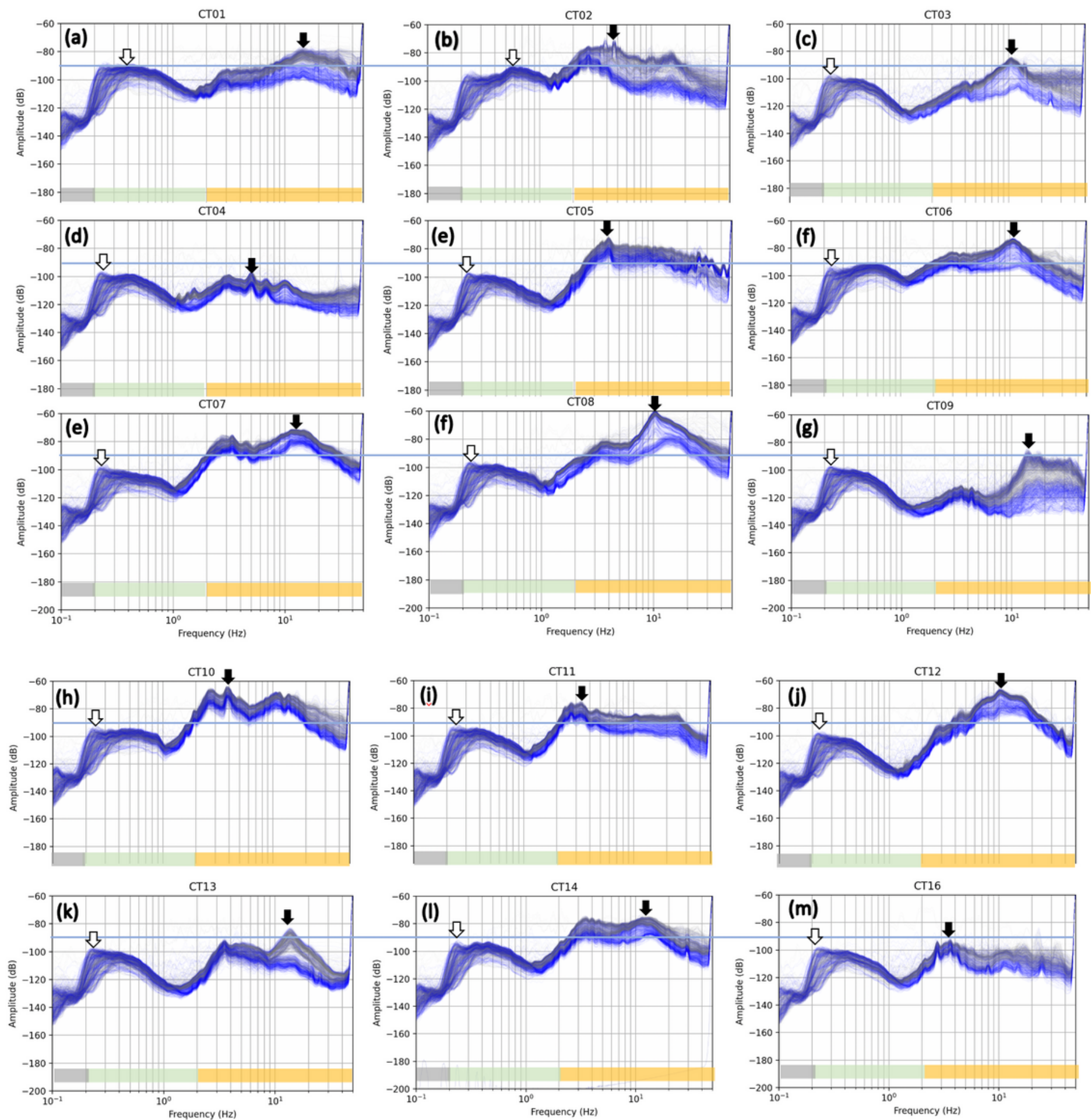

\section{Figure 3}

PSD at different stations in Taipei city. The hourly vertical seismogram from January of 2019 is processed for the plots. Grey and blue lines indicate the data from day ( $6 \mathrm{am}$ to $6 \mathrm{pm}$ ) and night ( $6 \mathrm{pm}$ to $6 \mathrm{am})$, respectively. The horizonal bar denotes three different frequency bands of $>2 \mathrm{~Hz}, 0.2-1 \mathrm{~Hz},<0.2$ $\mathrm{Hz}$. Black and white arrows indicate the largest amplitude in $>2 \mathrm{~Hz}$ and $0.2-1 \mathrm{~Hz}$ bands, respectively. Each 
curve represents hourly data during the two-month study period. Blue horizontal line denotes $-90 \mathrm{~dB}$ for a reference.
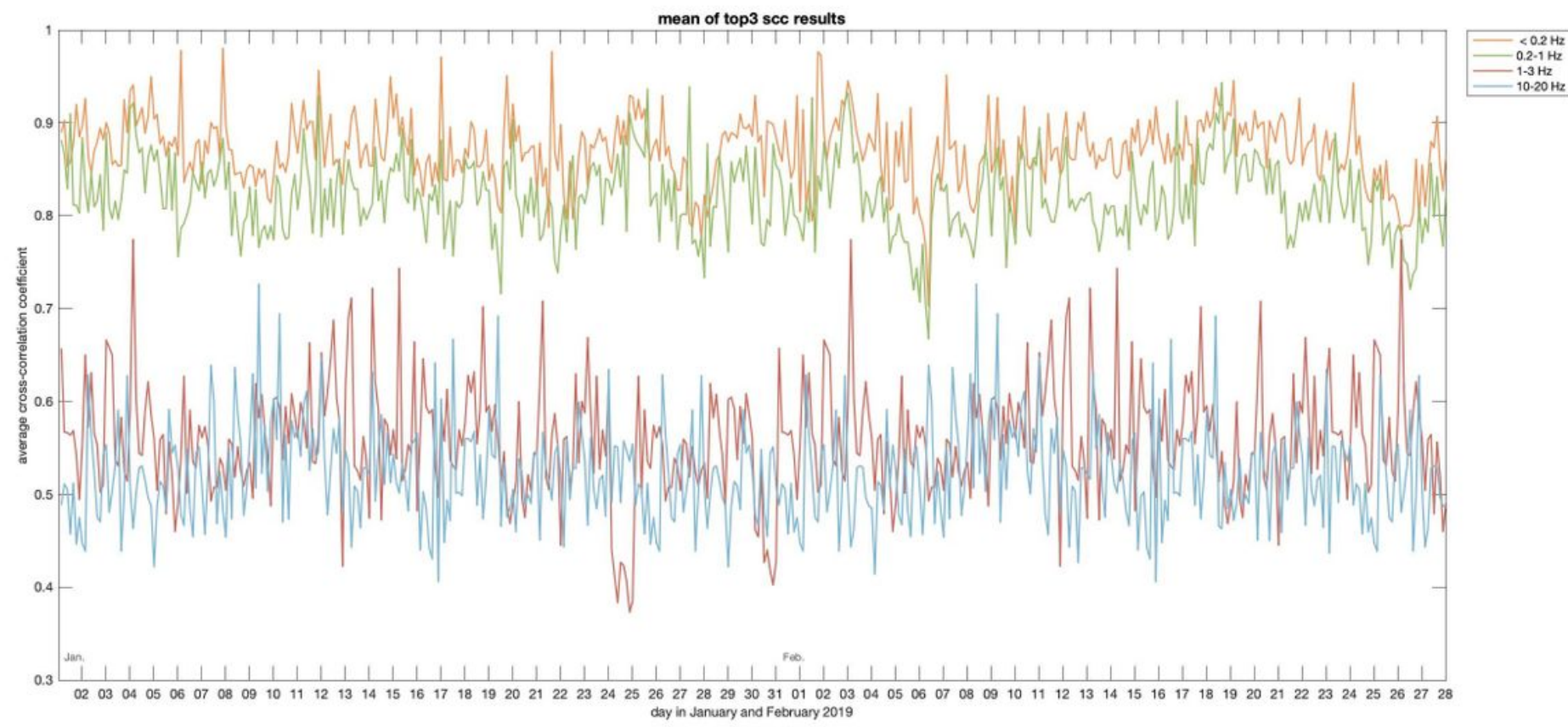

\section{Figure 4}

The average cross-correlation coefficients (ccc) obtained from the station pairs in the city as a function of time. Here the ccc was computed every sixty seconds and averaged over three hours for the three station pairs showing the highest ccc. 
(a)

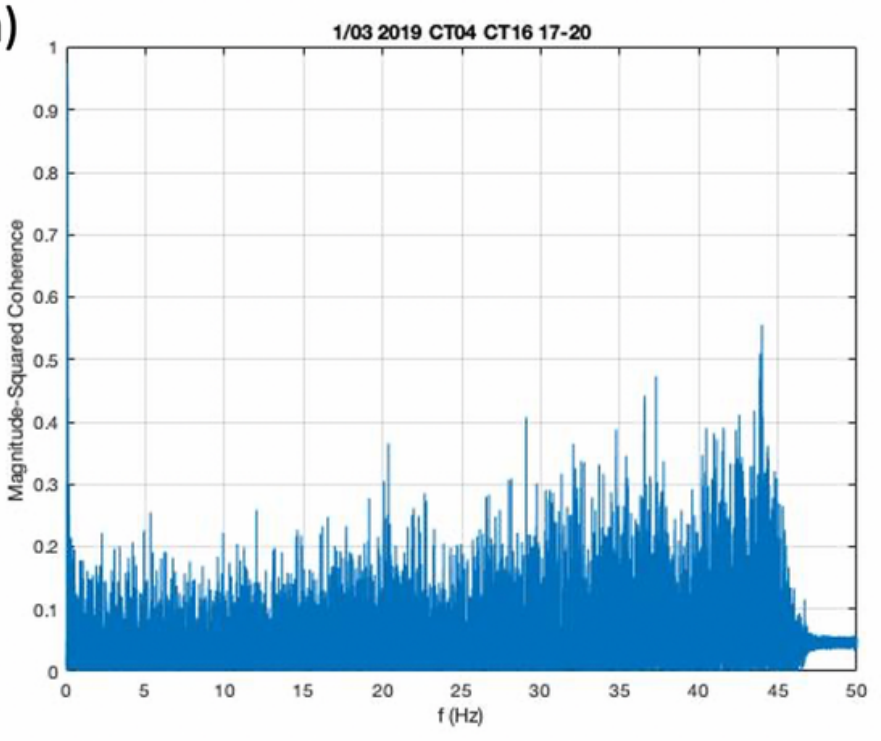

(c)

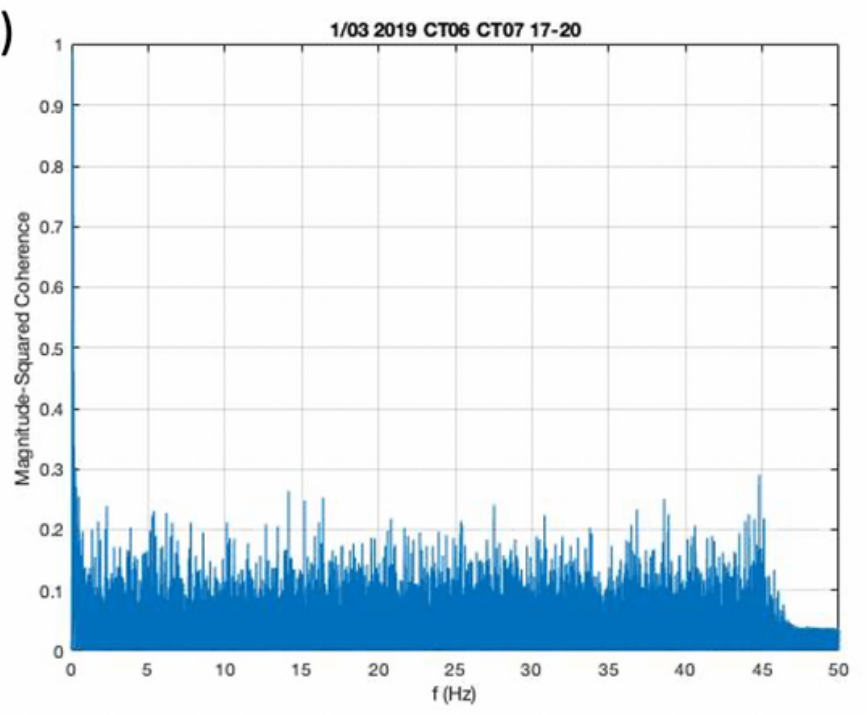

(b)

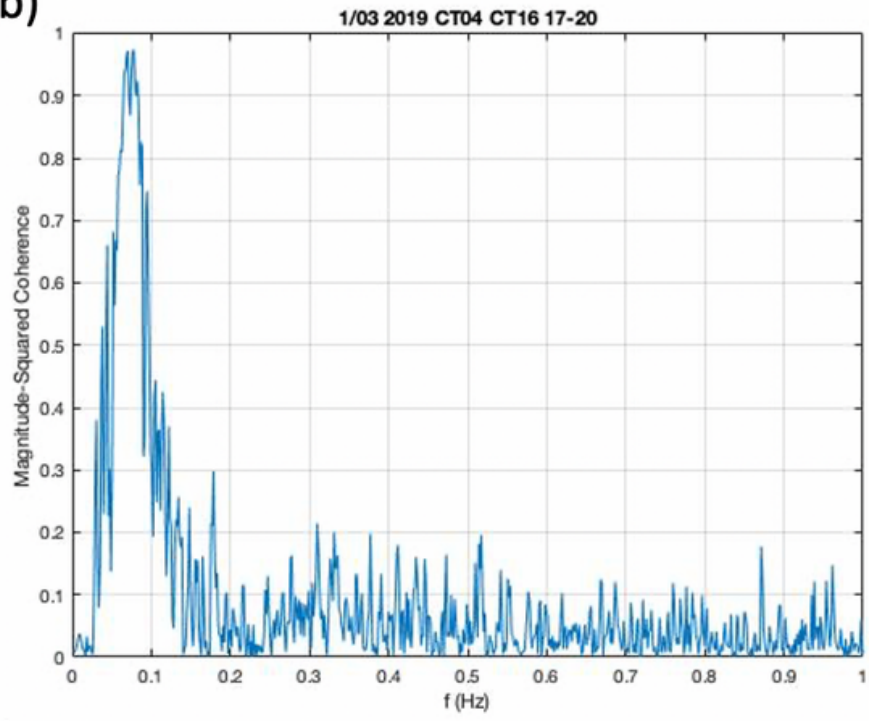

(d)

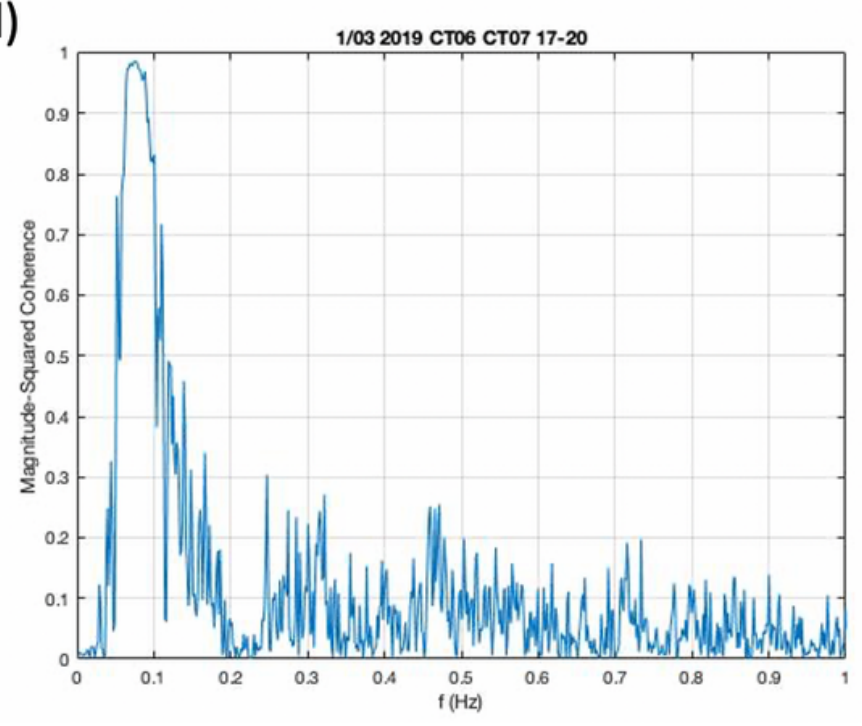

Figure 5

The average magnitude-squared coherence for quite stations CT04 and CT16 (a-b) and noisy stations CT06 and CT07 (c-d) using the four hours data (5 - 8 pm) on January 3, 2019. (b) and (d) are the close-up of (a) and (c) in the frequency range of smaller than $1 \mathrm{~Hz}$, respectively. 

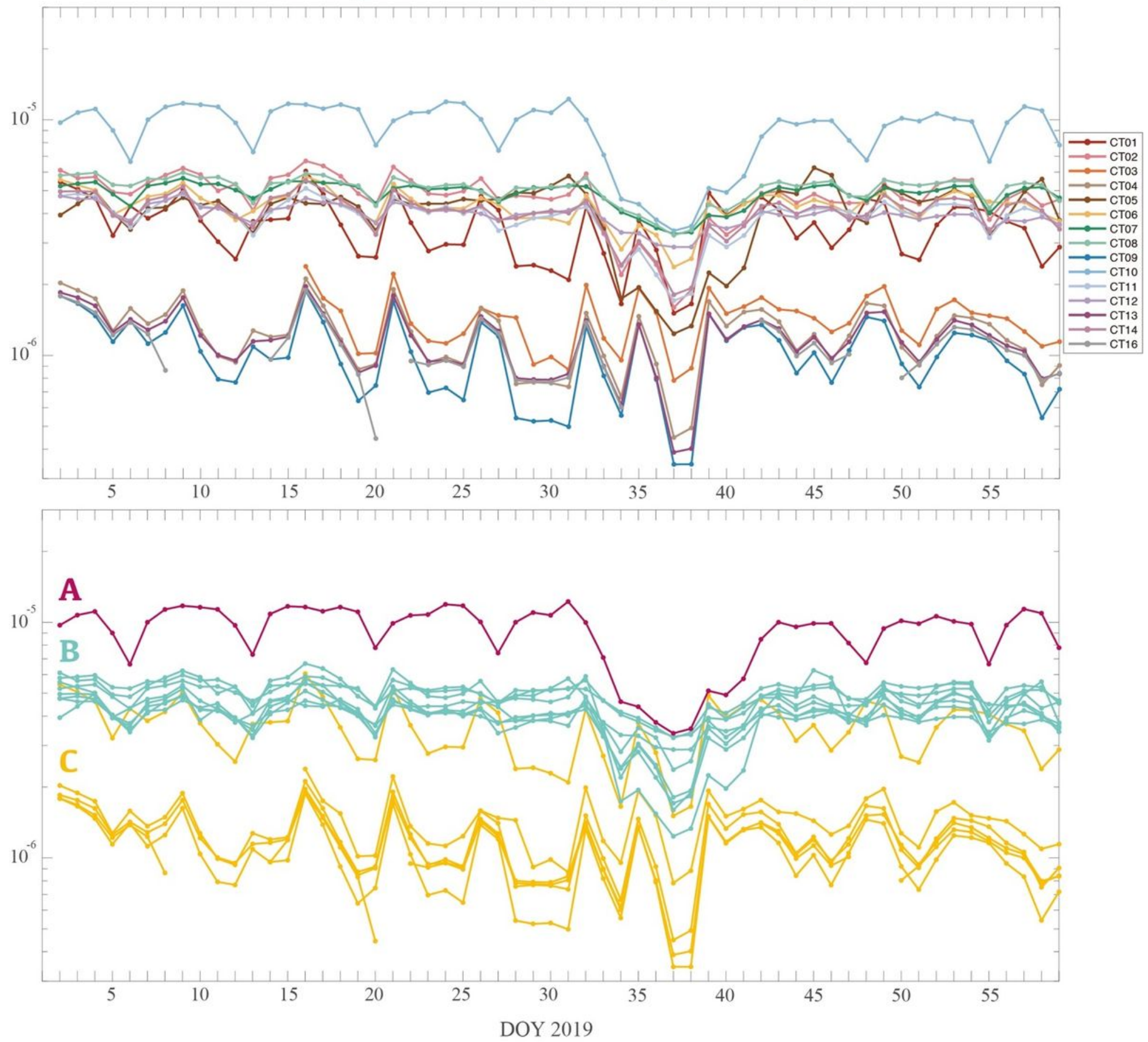

Figure 6

The median values of daily amplitude (no-filter applied) at different stations, color coded by station names (upper panel) and station groups (lower panel). 

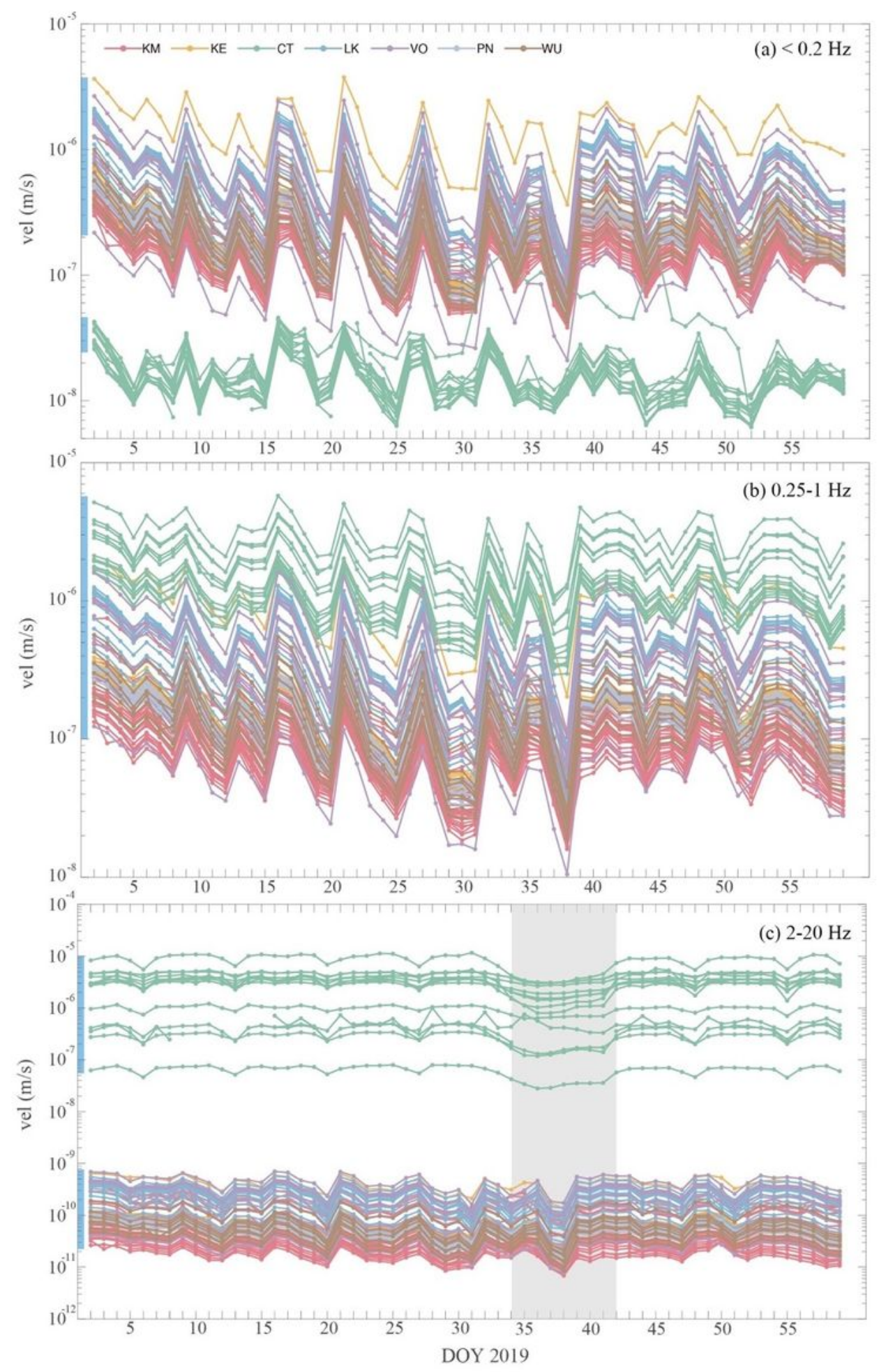

\section{Figure 7}

The median values of the daily amplitude at stations in different subareas for three frequency bands: (a) $<0.2 \mathrm{~Hz}$, (b) $0.25-1 \mathrm{~Hz}$, and (c) 2-20 Hz. DOY, day of year. The blue vertical bar on the y-axis shows the range of first points in the two-month time-series for the various stations. The grey vertical area in (c) indicates the Chinese New Year holiday. 
(a)

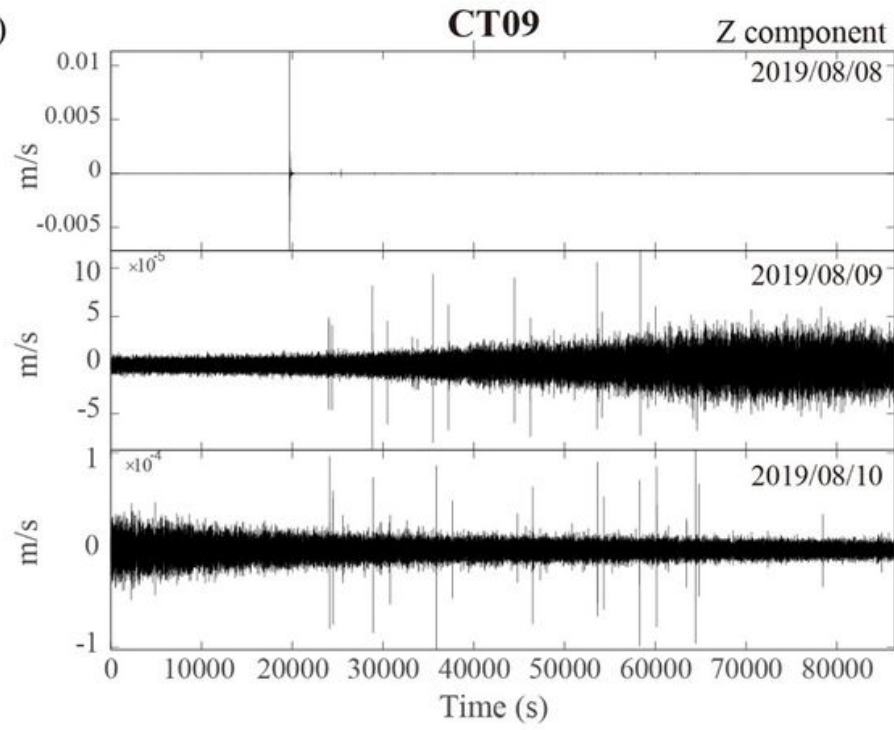

(c)

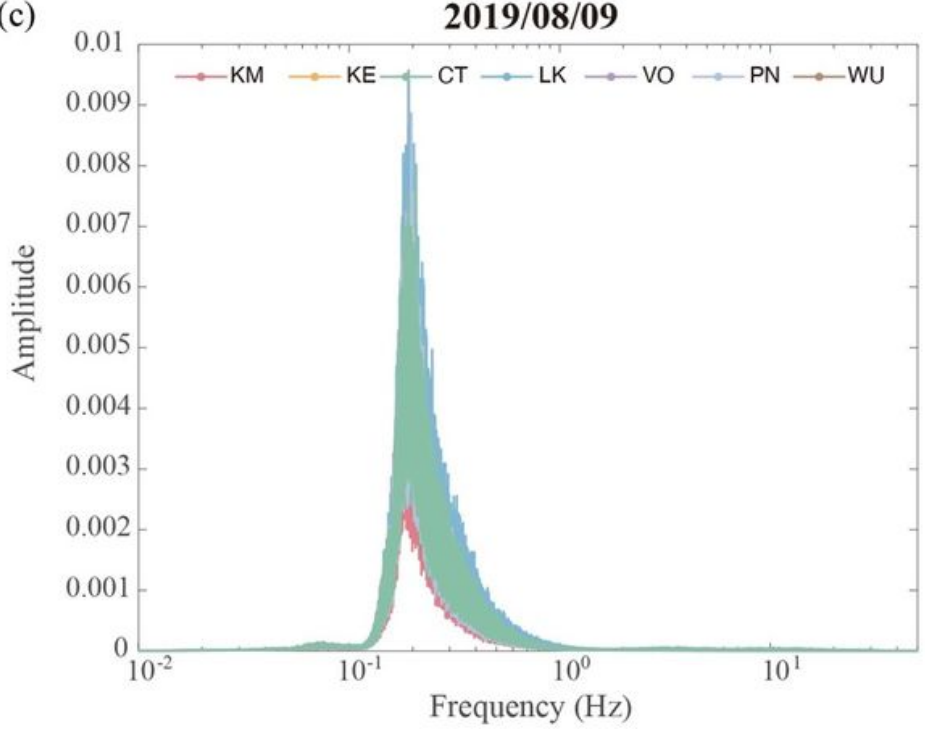

(b) $2019 / 08 / 08$

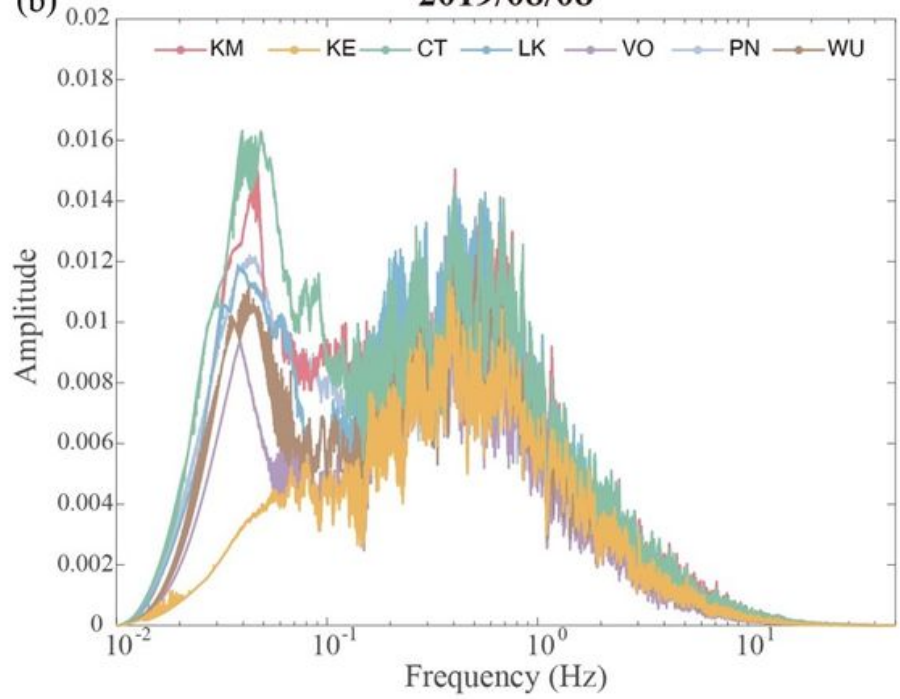

(d)

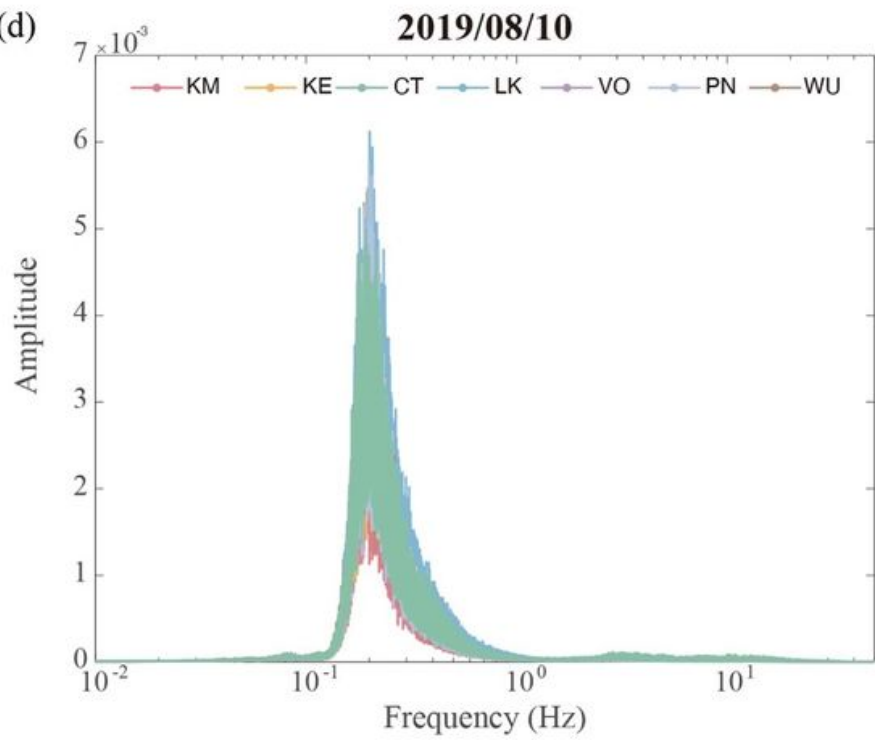

Figure 8

(a) The waveforms recorded at Station СT01 on August 8 to 10 (upper to bottom panels). The peak indicates a M6.2 earthquake near Yilan. (b-d) The median spectra from different subareas of the FA on August 8, 9, and 10 .

\section{Supplementary Files}

This is a list of supplementary files associated with this preprint. Click to download.

- Supplementarylnformation.pdf 